\title{
SISTEM AGROFORESTRI DATARAN TINGGI DAN DATARAN RENDAH KABUPATEN MINAHASA SELATAN PROVINSI SULAWESI UTARA
}

\section{AGROFORESTRY SYSTEM AT HIGHLAND AND LOWLAND OF SOUTH MINAHASA REGENCY, NORTH SULAWESI PROVINCE}

\author{
Andreas A. T. Suli'1), Jailani Husain ${ }^{2)}$ dan Hengki D. Walangitan') \\ 1)Mahasiswa Agronomi Pascasarjana Unsrat Manado, 95115 \\ 2)Dosen Agronomi Pascasarjana Unsrat Manado, 95115
}

\begin{abstract}
South Minahasa Regency have a topography that varied from lowland to highland. Until now there has been no research on differences in the performance of agroforestry systems of lowland and highland agroecological zones. The purposes of this study were to analyze the diversity of plant species and to estimate the biomass amount of agroforestry systems at lowland and highland agroecological zones. The research was carried out from October to December 2017 at two different agroecological zones, namely; the highland (Mokobang Village) and the lowland (Blongko Village). The results showed that there were 21 plant species at lowland having 4 plant species in average, while 30 plant species were found in the highland with 6 plant species in average. The biomass of 0.25 to $13.11 \mathrm{Mg} \mathrm{ha}^{-1}$ with an average of $3.47 \mathrm{Mg} \mathrm{ha}^{-1}$ was found at lowland, whereas the highland contained 0.34 to $98.65 \mathrm{Mg} \mathrm{ha}^{-1}$ with an average of $27.40 \mathrm{Mg} \mathrm{ha}^{-1}$ biomass. It is concluded that in South Minahasa Regency the highland agroforestry system had more plant species and had more carbon sequestration than that of lowland.

Keywords : agroforestry, highland zone, lowland zone
\end{abstract}

\begin{abstract}
ABSTRAK
Kabupaten Minahasa Selatan mempunyai topografi yang beragam mulai dari dataran rendah hingga dataran tinggi. Sampai saat ini belum ada penelitian tentang perbedaan keragaan sistem agroforestri klasifikasi zona agroekologi dataran rendah dan tinggi. Tujuan penelitian ini adalah menganalisis keragaman jenis tanaman dan memprakirakan jumlah biomassa pada sistem agroforestri zona agroekologi dataran rendah dan tinggi. Penelitian ini berlangsung sejak Oktober sampai Desember 2017 di dua zona agroekologi yaitu dataran tinggi (desa Mokobang) dan dataran rendah (desa Blongko). Hasil penelitian menunjukan bahwa pada sistem agroforestri dataran rendah terdapat 21 jenis tanaman, dengan rata-rata 4 jenis tanaman, sedangkan di dataran tinggi terdapat 30 jenis tanaman dengan rata-rata 6 jenis tanaman. Biomassa sebesar 0,25 hingga 13,11 Mg ha-1 dengan rata-rata sebesar 3,47 Mg ha-1 terkandung pada dataran rendah berkisar, sedangkan di dataran tinggi jumlah biomassa berkisar antara 0,34 sampai $98,65 \mathrm{Mg} \mathrm{ha}^{-1}$, dengan rata-rata $27,40 \mathrm{Mg} \mathrm{ha}^{-1}$. Kesimpulanya adalah bahwa di Kabupaten Minahasa Selatan jumlah jenis dan tanaman pengikat karbon pada sistem agroforestri dataran tinggi lebih banyak dari pada dataran rendah.
\end{abstract}

Kata kunci : agroforestri, dataran tinggi, dataran rendah

Eugenia Volume 24 No. 1 Pebruari 2018 


\section{PENDAHULUAN}

Sistem agroforestri adalah istilah kolektif dari berbagai pemanfaatan lahan terpadu (kehutanan, pertanian, dan/atau peternakan) yang ada di berbagai tempat di belahan bumi, tidak terkecuali yang dijumpai di Indonesia. Nair (1993) membuat suatu klasifikasi yang mengelompokan sistem agroforestri berdasarkan klasifikasi zona agroekologi menjadi beberapa region atau zona antara lain dataran rendah lembab (humid lowland), dan dataran tinggi (highland).

Purwanti (2007) melaporkan hasil penelitian yang dilaksanakan di lahan-lahan yang menerapkan sistem agroforestri di Kelurahan Gantarang, Kecamatan Tinggi Moncong, Kabupaten Gowa, Sulawesi Selatan (500-700 mdpl) bahwa petani memperoleh sumber pendapatan dari 8 tanaman. Sistem agroforestri kompleks yang dilaksanakan oleh petani di dataran rendah Filipina membudidayakan 122 spesies tanaman untuk 77 tujuan (Langenberger, dkk., 2009). Achmad dan Purwanto (2014) melaporkan bahwa semakin rendah topografi tempat tumbuh, semakin beragam pola tanam dan jenis tanaman yang dikembangkan.

Kabupaten Minahasa Selatan mempunyai topografi yang beragam mulai dari dataran rendah hingga dataran tinggi. Sampai saat ini belum ada penelitian tentang perbedaan keragaan sistem agroforestri klasifikasi zona agroekologi dataran rendah dan tinggi. Tujuan penelitian ini adalah menganalisis komposisi tanaman dan biomassa sistem agroforestri pada agroekologi dataran rendah dan dataran tinggi di Kabupaten Minahasa Selatan Provinsi Sulawesi Utara. Manfaat yang diharapkan dari penelitian ini adalah untuk menjadi sumber data dan informasi tentang komposisi tanaman dan biomassa pada masing-masing lahan sistem agroforestri agroekologi dataran rendah dan dataran tinggi, dalam rangka terjadi perbaikan fungsi ekologi pada lahan-lahan yang terdapat di Sulawesi Utara khususnya Minahasa Selatan di masa depan.

\section{METODE PENELITIAN}

Penelitian dilakukan di dua desa, Desa Mokobang Kecamatan Modoinding Kabupaten
Minahasa Selatan yang mewakili daerah zona agroekologi dataran tinggi dan Desa Blongko Kecamatan Sinonsayang yang mewakili daerah zona agroekologi dataran rendah, dan berlangsung dari bulan Oktober sampai Desember 2017. Pengambilan sampel dilakukan secara sengaja dengan memilih 15 orang petani pada masingmasing desa dengan lahan yang ditanami tanaman pohon dan tanaman semusim (Agrisilvikultur).

Alat dan bahan yang digunakan dalam penelitian ini adalah meteran, tali plastik, alat tulis menulis, kamera, label, laptop dengan Software MS Excel, Peta RBI skala $1: 50.000$ tahun 2008 dan GPS Receiver.

Data yang diambil di lapangan adalah biodata pemilik dan data biofisik lahan (berupa nama jenis tanaman dan diameter tanaman kayu, hasil analisis data luas lahan, jumlah jenis tanaman dan jumlah biomassa dikonversi ke satuan ha-1). Sampel data yang dianalisis dalam penelitian ini adalah nama jenis tanaman dan biomassa cara analisnya adalah:

Nama jenis tanaman. Masyarakat ditanyakan semua jenis tanaman yang ditanam di lahan, kemudian dijumlahkan untuk mendapat total jumlah jenis pada lahan tersebut, kemudian diperiksa di lahan tersebut. Dalam rangka melakukan perbandingan antara dua zona agroekologi, maka perlu dilihat kesamaan Jenis pada kedua tempat tersebut, dengan menggunakan persamaan yang dikemuka-kan Sorenson (1948) :

$$
\mathrm{IS}=\frac{2 \mathrm{C}}{\mathrm{A}+3} \times 100 \%
$$

IS adalah presentasi Indeks Sorenson antara tempat $A$ dan tempat $B$. A adalah jumlah jenis tempat $A$ dan $B$ adalah jumlah jenis tempat $B$. $C$ adalah jumlah jenis yang terdapat di tempat $A$ dan B.

Frekuensi suatu jenis tanaman merupakan indikator untuk mengukur tingginya ketertarikan masyarakat terhadap jenis tersebut ataupun tingginya kemampuan tumbuh dan berkembang jenis tersebut pada habitatnya Sistem Agroforestri Dataran Rendah ataupun Dataran Tinggi. Rumus 
untuk menganalisis Frekuensi Relatif masingmasing jenis tanaman adalah :

$$
F=\frac{\sum N_{i}}{\sum N_{T}}
$$

$\mathrm{F}$ adalah Frekuensi, $\Sigma \mathrm{N}_{\mathrm{i}}$ adalah jumlah lahan yang ditemukan suatu jenis tanaman dan $\Sigma N_{T}$ adalah jumlah sampel lahan pada masing-masing desa (15 lahan).

Biomassa. Keliling batang pohon setinggi dada $\left(130 \mathrm{~cm}\right.$ diatas permukaan tanah) $\left(\mathrm{cm}^{2}\right)$ diukur untuk mendapatkan diameter pohon lalu dianalisis biomassa pohon. Rumus untuk men- dapatkan diameter dari keliling batang pohon adalah menggunakan rumus lingkaran yaitu:

$$
\mathrm{D}=\mathrm{K} \pi^{-1} \text {. }
$$

$\mathrm{D}$ adalah diameter dalam $\mathrm{cm}$ dan $\mathrm{K}$ adalah keliling dalam $\mathrm{cm}$. Hasil diameter dihitung biomassa menggunakan rumus allometrik biomassa yang dikemukakan Ketterings et al. (2001) :

$$
W=0,11 \rho D^{2,62}
$$

$W$ adalah biomassa dalam $\mathrm{kg}$ dan $\rho$ adalah massa jenis kayu dalam $\mathrm{g} \mathrm{cm}^{-3}$ yang diambil dari beberapa pustaka yang dijelaskan di Tabel 1. Data biomassa yang diambil hanya dari pohon yang sudah memiliki diameter diatas $10 \mathrm{~cm}$.

Tabel 1. Massa Jenis Kayu

(Table 1. Wood Density)

\begin{tabular}{llll}
\hline \multicolumn{1}{c}{ Nama Lokal } & \multicolumn{1}{c}{ Nama Ilmiah } & $\begin{array}{c}\text { Massa Jenis } \\
\left(\mathrm{g} \mathrm{cm}^{-3}\right)\end{array}$ & \multicolumn{1}{c}{ Sumber } \\
\hline Jambu monyet & Anacardium occidentale & 0,468 & Zanne et al. (2009) \\
Nangka & Artocarpus heterophyllus & 0,53 & Zanne et al. (2009) \\
Marintek & Bischofia javanica & 0,64 & Zanne et al. (2009) \\
Bintangar & Calophyllum sp. & 0,55 & Zanne et al. (2009) \\
Kayu Manis & Cinnamomum burmannii & 0,46 & Zanne et al. (2009) \\
Pohon Koka & Dipterocarpus elongatus & 0,55 & Zanne et al. (2009) \\
Pedu & Dryobalanops aromatica & 0,68 & Zanne et al. (2009) \\
Durian & Durio sp. & 0,58 & Zanne et al. (2009) \\
Cempaka & Elmerrillia ovalis & 0,43 & Zanne et al. (2009) \\
Langsa & Lansium domesticum & 0,68 & Zanne et al. (2009) \\
Lamtoro & Leucaena sp. & 0,52 & Zanne et al. (2009) \\
Kayu Telor & Nauclea orientalis & 0,483 & Zanne et al. (2009) \\
Rambutan & Nephelium lappaceum & 0,73 & Zanne et al. (2009) \\
Sangkongan & Ochrosia acuminate & 0,42 & Zanne et al. (2009) \\
Nantu & Palaquium sp. & 0,56 & Anonim (2008) \\
Pangi & Pangium edule & 0,519 & Zanne et al. (2009) \\
Sengon & Paraserianthes falcataria & 0,33 & Anonim (2008) \\
Alpukat & Persea Americana & 0,52 & Miles and Smith (2009) \\
Terembuk & Pinus merkusii & 0,53 & Zanne et al. (2009) \\
Matoa & Pometia sp. & 0,785 & Anonim (2008) \\
Linggua & Pterocarpus indicus & 0,65 & Anonim (2008) \\
Kayu Loyang & Quercus sp. & 0,70 & Zanne et al. (2009) \\
Meranti & Shorea sp & 0,558 & Anonim (2008) \\
Mahoni & Swietenia sp. & 0,625 & Anonim (2008) \\
Coklat & Theobroma cacao & 0,42 & Zanne et al. (2009) \\
Tayapu & Trema orientalis & 0,315 & Zanne et al. (2009) \\
\hline & & & \\
& & &
\end{tabular}




\section{HASIL DAN PEMBAHASAN}

\section{Jenis Tanaman}

Frekuensi masing-masing jenis pada sistem agroforestri dataran tinggi dan dataran rendah ditunjukan pada Tabel 2. Tanaman cempaka (Elmerrillia ovalis) memiliki nilai $F$ tertinggi tidak hanya pada kategori tanaman kayu tapi juga seluruh tanaman yang ada di sistem agroforestri dataran tinggi. Masyarakat memanfaatkan kayu cempaka sebagai bahan bangunan rumah merupakan salah satu alasan mengapa cempaka sering ditanam. Alasan lain nilai $F$ tertinggi dimiliki oleh cempaka, karena berdasarkan hasil interview, sekitar tahun 2007 pemerintah melakukan tindakan penghijauan kembali dengan menanam bibit pohon dan salah satunya cempaka. Sisa bibit kemudian dibawa warga dan ditanam di tepi lahan (Gambar 1a). Tayapu (Trema orientalis) menempati urutan kedua dalam nilai $F$, karena memiliki kayu lunak sehingga tanaman ini cepat tumbuh di ruang lahan yang tidak dimanfaatkan petani. Kayu Mahoni (Swietenia sp.) sering dimanfaatkan sebagai bahan bangunan oleh masyarakat itulah alasan masyarakat menanam tanaman ini, sehingga menempati urutan ketiga nilai $F$. Terembuuk (Casuarina equisetifolia) yang menempati urutan keempat nilai $\mathrm{F}$ adalah tanaman yang memiliki habitat asli di daerah dataran tinggi, selain karena daun jarumnya tidak menaungi tanaman utama petani tidak menebang pohon ini di lahan karena sering dijadikan pembatas lahan (Gambar 1b).

Kayu Loyang (Quercus sp.), Bintangar (Calophyllum sp.), Kayu Telor (Nauclea orientalis), Nantu (Palaquium sp.), Marintek (Bischofia javanica), dan Meranti (Shorea sp.) merupakan tanaman yang juga sering dijadikan bahan bangunan, tapi karena tidak adanya bantuan bibit oleh pemerintah seperti cempaka, maka tanamantanaman tersebut tidak banyak ditanam oleh petani. Kayu manis (Cinnamomum burmannii) merupakan tanaman yang ditanam dengan pola pagar oleh salah satu sampel petani untuk diambil batang, cabang dan daunnya untuk dipergunakan dan dijual (Gambar 1c). Para petani juga mencoba membudidayakan cengkih (Syzygium aromaticum) di lahan (Gambar 1d).
Tanaman-tanaman pohon yang buahnya dimanfaatkan petani seperti, Alpukat (Persea Americana), Mangga (Mangifera indica), Rambutan (Nephelium lappaceum), Coklat (Theobroma cacao), Durian (Durio sp.), Langsa (Lansium domesticum), pohonnya dimanfaatkan sebagai tempat berteduh (Mangga dan Alpukat) dan juga sebagai pembatas lahan. Jagung (Zea mays) dan Bawang (Allium fistulosum) merupakan tanaman dengan nilai $F$ tertinggi untuk tanaman semusim di sistem agroforestri dataran tinggi. Jagung selain untuk dijual, juga dimanfaatkan sebagai pakan unggas dan babi (bungkil jagung) juga sebagai makanan utama (dimasak bersama dengan beras). Hasil panen tanaman Bawang (Allium fistulosum), Cabai (Capsicum annuum), Akar Kuning (Daucus carota), Labu (Cucurbita moschata), Kacang Merah (Vigna angularis), Kacang Tanah (Arachis Hypogaea), Kentang (Solanum tuberosum), dan Kacang Panjang (Vigna unguiculata sesquipedalis) kebanyakan dijual dan yang lain digunakan untuk keperluan dapur dan bibit untuk periode penanaman selanjutnya. Tanaman Jahe (Zingiber officinale), Kokuru (Ocimum sp.), dan Ubi Bete (Colocasia esculenta) merupakan tanaman sisipan.

Di sistem agroforestri dataran rendah, Nantu (Palaquium sp.), Linggua (Pterocarpus indicus), Bintangar (Calophyllum sp.), Kayu Telor (Nauclea orientalis), Sengon (Paraserianthes falcataria), dan Pohon Koka (Dipterocarpus elongates) merupakan tanaman yang sudah lama ditanam dan jarang diambil kayunya karena berfungsi sebagai pembatas lahan (Gambar 2a). Mangga (Mangifera indica) yang memiliki tajuk yang besar dan rimbun sering dijadikan tempat berteduh dari terik matahari oleh petani saat beristirahat (Gambar 2b). Tanaman-tanaman berikut selain untuk pembatas lahan bagian tanaman juga digunakan, Matoa (Pometia sp.), Lemon Nipis (Citrus aurantifolia), Durian (Durio sp.), Rambutan (Nephelium lappaceum), Alpukat (Persea Americana), dan Lemon Cui (Citrus microcarpa) buahnya digunakan untuk makanan ataupun bumbu masakan, sedangkan Pangi (Pangium edule), daunnya digunakan sebagai makanan. 
Tabel 2. Frekuensi Relatif Jenis-jenis Tanaman di Sistem Agrofrestri Dataran Tinggi dan Dataran Rendah

(Table 2. Relative Frequency of Plant Species at Highland and Lowland Agroforestry System )

\begin{tabular}{|c|c|c|c|c|c|c|}
\hline \multirow{2}{*}{ No. } & \multicolumn{2}{|c|}{ Sistem Agrofrestri Dataran Tinggi } & \multicolumn{4}{|c|}{ Sistem Agrofrestri Dataran Rendah } \\
\hline & Nama Daerah & Nama IImiah & $\mathrm{F}$ & Nama Daerah & Nama IImiah & $\bar{F}$ \\
\hline \multicolumn{7}{|c|}{ Tanaman Kayu } \\
\hline 1. & Cempaka & Elmerrillia ovalis & 0,87 & Nantu & Palaquium sp. & 0,13 \\
\hline 2. & Tayapu & Trema orientalis & 0,67 & Linggua & Pterocarpus indicus & 0,13 \\
\hline 3. & Mahoni & Swietenia sp. & 0,27 & Bintangar & Calophyllum sp. & 0,07 \\
\hline 4. & Terembuuk & $\begin{array}{l}\text { Casuarina } \\
\text { equisetifolia }\end{array}$ & 0,2 & Kayu Telor & Nauclea orientalis & 0,07 \\
\hline 5. & Kayu Loyang & Quercus sp. & 0,13 & Sengon & $\begin{array}{l}\text { Paraserianthes } \\
\text { falcataria }\end{array}$ & 0,07 \\
\hline 6. & Bintangar & Calophyllum sp. & 0,07 & Pohon Koka & $\begin{array}{l}\text { Dipterocarpus } \\
\text { elongates }\end{array}$ & 0,07 \\
\hline 7. & Kayu Telor & Nauclea orientalis & 0,07 & & & \\
\hline 8. & Nantu & Palaquium sp. & 0,07 & & & \\
\hline 9. & Marintek & Bischofia javanica & 0,07 & & & \\
\hline 10. & Meranti & Shorea sp. & 0,07 & & & \\
\hline 11. & Kayu Manis & $\begin{array}{l}\text { Cinnamomum } \\
\text { burmannii }\end{array}$ & 0,07 & & & \\
\hline \multicolumn{7}{|c|}{ Tanaman Buah-buahan } \\
\hline 1. & Alpukat & Persea Americana & 0,27 & Mangga & Mangifera indica & 0,33 \\
\hline 2. & Mangga & Mangifera indica & 0,13 & Matoa & Pometia sp. & 0,27 \\
\hline 3. & Rambutan & $\begin{array}{l}\text { Nephelium } \\
\text { lappaceum }\end{array}$ & 0,3 & Durian & Durio sp. & 0,2 \\
\hline 4. & Coklat & Theobroma cacao & 0,13 & Rambutan & $\begin{array}{l}\text { Nephelium } \\
\text { lappaceum }\end{array}$ & 0,13 \\
\hline 5. & Durian & Durio sp. & 0,07 & Alpukat & Persea Americana & 0,07 \\
\hline 6. & Langsa & $\begin{array}{l}\text { Lansium } \\
\text { domesticum }\end{array}$ & 0,07 & Pangi & Pangium edule & 0,07 \\
\hline \multicolumn{7}{|c|}{ Tanaman Pertanian } \\
\hline 1. & Jagung & Zea mays & 0,53 & Jagung & Zea mays & 0,6 \\
\hline 2. & Bawang & Allium fistulosum & 0,53 & Cabai & Capsicum annuum & 0,47 \\
\hline 3. & Cabai & Capsicum annuum & 0,33 & Pisang & Musa spp. & 0,4 \\
\hline 4. & Jahe & Zingiber officinale & 0,27 & Kelapa & Cocos nucifera & 0,33 \\
\hline 5. & Akar Kuning & Daucus carota & 0,2 & Lemon Nipis & Citrus aurantifolia & 0,27 \\
\hline 6. & Labu & $\begin{array}{l}\text { Cucurbita } \\
\text { moschata }\end{array}$ & 0,2 & Ubi Kayu & Manihot esculenta & 0,13 \\
\hline 7. & Kacang Merah & Vigna angularis & 0,13 & Lemon Cui & Citrus microcarpa & 0,07 \\
\hline 8. & Kacang Tanah & Arachis hypogaea & 0,13 & Pepaya & Carica papaya & 0,07 \\
\hline 9. & Kentang & $\begin{array}{l}\text { Solanum } \\
\text { tuberosum }\end{array}$ & 0,13 & Cengkih & $\begin{array}{l}\text { Syzygium } \\
\text { aromaticum }\end{array}$ & 0,07 \\
\hline 10. & Ubi Bete & $\begin{array}{l}\text { Colocasia } \\
\text { esculenta }\end{array}$ & 0,13 & & & \\
\hline 11. & Kacang Panjang & $\begin{array}{l}\text { Vigna unguiculata } \\
\text { sesquipedalis }\end{array}$ & 0,07 & & & \\
\hline 12. & Cengkih & $\begin{array}{l}\text { Syzygium } \\
\text { aromaticum }\end{array}$ & 0,07 & & & \\
\hline 13. & Kokuru & Ocimum sp. & 0,07 & & & \\
\hline
\end{tabular}

Sumber: Hasil Interview dan Survey Lapangan dengan Petani November-Desember 2017 


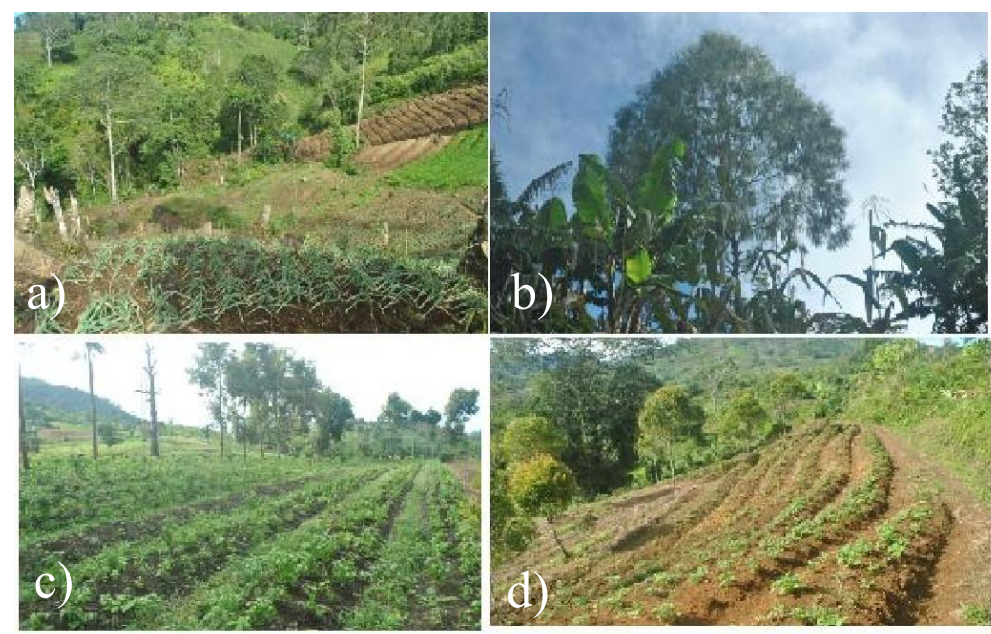

Gambar 1. Kondisi Lahan di Sistem Agroforestri Dataran Tinggi

(Figure 1. Fields Condition at Highland Agroforestry System)

Tanaman pisang (Musa spp.) memiliki frekuensi tertinggi karena sering dijadikan makanan pisang goreng ataupun dijual di pasar. Pepaya (Carica papaya) merupakan tanaman sisipan yang diambil buahnya untuk dimakan dan dijual. Tanaman jagung (Zea mays) selain dijual, juga dimanfaatkan sebagai pakan unggas dan babi seperti di sistem agroforestri dataran tinggi. Hasil panen tanaman cabai (Capsicum annuum) selain dijual ada juga yang disimpan petani untuk rempah di dapur dan sebagian disimpan sebagai bibit untuk periode penanaman selanjutnya. Ubi Kayu (Manihot esculenta) merupakan tanaman sisipan yang hasilnya sering dikonsumsi sendiri oleh petani sebagai makanan pengganti nasi (Gambar 2c).

Sistem agroforestri dataran rendah, ditemukan sebanyak 21 jenis tanaman secara keseluruhan dalam lahan sistem agroforestri, yang terdiri dari 12 jenis tanaman pohon (kayu-kayuan dan buah-buahan) dan 9 jenis tanaman pertanian. Sistem agrofrestri dataran tinggi, ditemukan sebanyak 30 jenis tanaman di lahan sistem agroforestri, yang terdiri dari 17 tanaman pohon (kayukayuan dan buah-buahan) dan 13 jenis tanaman pertanian. Hasil penelitian menujukkan terdapat 10 jenis tanaman yang terdapat di kedua tempat tersebut. Wijayanto dan Hartoyo (2015) melaporkan bahwa pada sistem agroforestri di Kabupaten Lampung Barat dan Purwakarta, ditemukan 77 jenis tanaman, yang terdiri dari 53 tanaman pohon (kayu- kayuan dan buah-buahan) dan 24 jenis tanaman pertanian. Sebagai perbandingan, di hutan alam yang masuk dalam kawasan KPHP Poigar ditemukan 78 jenis pohon (Wahyuni dan Mokodompit, 2016). Jumlah Jenis 4 tempat tersebut terlihat di Gambar 3.

Hasil analisis dengan menggunakan persamaan yang dikemukakan oleh Sorenson (1948), ditemukan Presentasi Indeks Sorenson dari Desa Mokobang dan Blongko adalah sebesar 39,2\%. Penelitian lain di dua tempat dengan ketinggian yang berbeda (550-640 m dpl dan 1100-1150 m dpl) yang dilaksanakan oleh Mansur (2003) menunjukkan Presentasi Indeks Sorenson yang lebih kecil yaitu $19 \%$. Perbedaan yang lebih kecil tersebut kemungkinan terjadi karena jarak kedua tempat tersebut lebih jauh (berbeda kabupaten) dibandingkan dengan penelitian ini yang lebih dekat (dalam 1 kabupaten). Sebuah penelitian yang dilaksanakan oleh Mawazin dan Subiakto (2013) pada dua tempat yang masih dalam satu kawasan namun berbeda perlakuan (hutan belum ditebang dan hutan bekas tebangan) mendapati Presentasi Indeks Soranson mencapai 93,75\%. Hasil penelitian yang dilaksanakan oleh Mansur (2003) dan Mawazin dan Subiakto (2013) digabungkan dengan penelitian ini dapat disimpulkan Desa Blongko dan Desa Mokobang berbeda Zona Agroekologi. Jumlah jenis yang ditemukan di sistem agroforestri dataran tinggi dan dataran rendah 
Kabupaten Minahasa Selatan masih jauh lebih rendah dibanding sistem agroforestri di Kabupaten Lampung Barat dan Purwakarta dari jenis tanaman pertanian dan terutama jenis pohon. Dalam rangka peningkatan jumlah jenis, sistem agroforestri dataran tinggi dan dataran rendah harus ditanami lebih banyak jenis tanaman pertanian dan terutama jenis pohon agar mendekati jumlah jenis hutan alam KPHP Poigar atau menyamai jumlah jenis di Kabupaten Lampung Barat dan Purwakarta. Jumlah jenis di sistem agroforestri dataran tinggi lebih tinggi baik jenis tanaman pertanian dan pohon dibanding sistem agroforestri dataran rendah.

\section{Biomassa}

Berdasarkan hasil perhitungan di sistem agroforestri dataran tinggi dan dataran rendah, biomassa yang ada di lahan petani bervariasi. Berdasarkan hasil penelitian, jumlah biomassa yang terdapat pada masing-masing lahan di sistem agroforestri dataran rendah berkisar dari 0,25 -
$13,11 \mathrm{Mg} \mathrm{ha}^{-1}$ dengan rata-rata sebesar $3,47 \mathrm{Mg}$ ha-1. Di sistem agroforestri dataran tinggi jumlah biomassa berkisar antara 0,34 - 98,65 Mg ha-1, dengan rata-rata $27,40 \mathrm{Mg} \mathrm{ha}^{-1}$. Data biomassa pada masing-masing lahan di sistem agroforestri dataran tinggi dan dataran rendah terdapat lebih rinci pada Tabel 3.

Berdasarkan hasil penelitian, rata-rata biomassa atas permukaan di hutan primer Taman Nasional Gunung Halimun Salak Jawa Barat adalah $277,48 \mathrm{Mg}_{\text {ha-1}}{ }^{-1}$ (Arifanti, $d k k$., 2014). Hasil analisis di sistem agroforestri register 39 aatar setuju Kabupaten Tanggamus Provinsi Lampung menujukkan bahwa rata-rata biomassa atas permukaan di tempat tersebut adalah $247,63 \mathrm{Mg} \mathrm{ha}^{-1}$ (Aprianto, dkk., 2016). Perbandingan rata-rata biomassa atas permukaan hutan primer di Jawa Barat, sistem agroforestri di Lampung dan sistem agroforestri dataran tinggi dan dataran rendah Kabupaten Minahasa Selatan dijelaskan lebih rinci di Gambar 4.

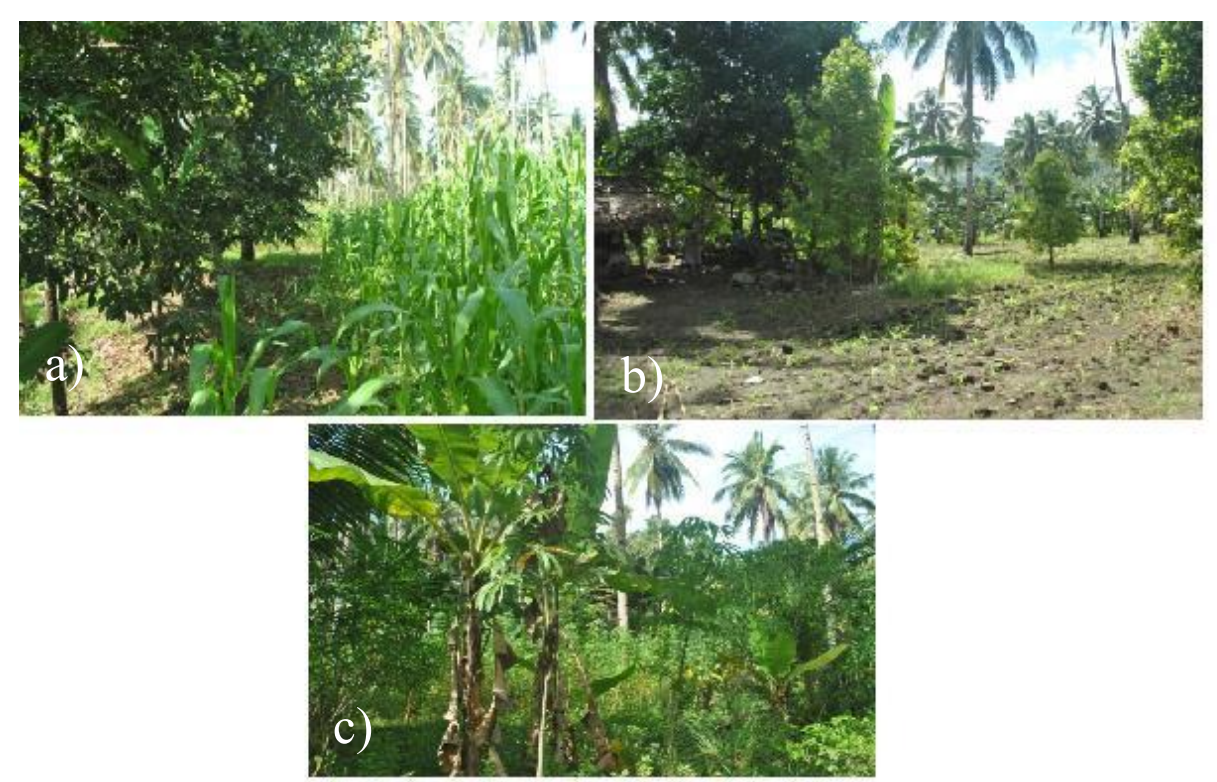

Gambar 2. Kondisi Lahan di Sistem Agroforestri Dataran Rendah

(Figure 2. Fields Condition at Lowland Agroforestry System 


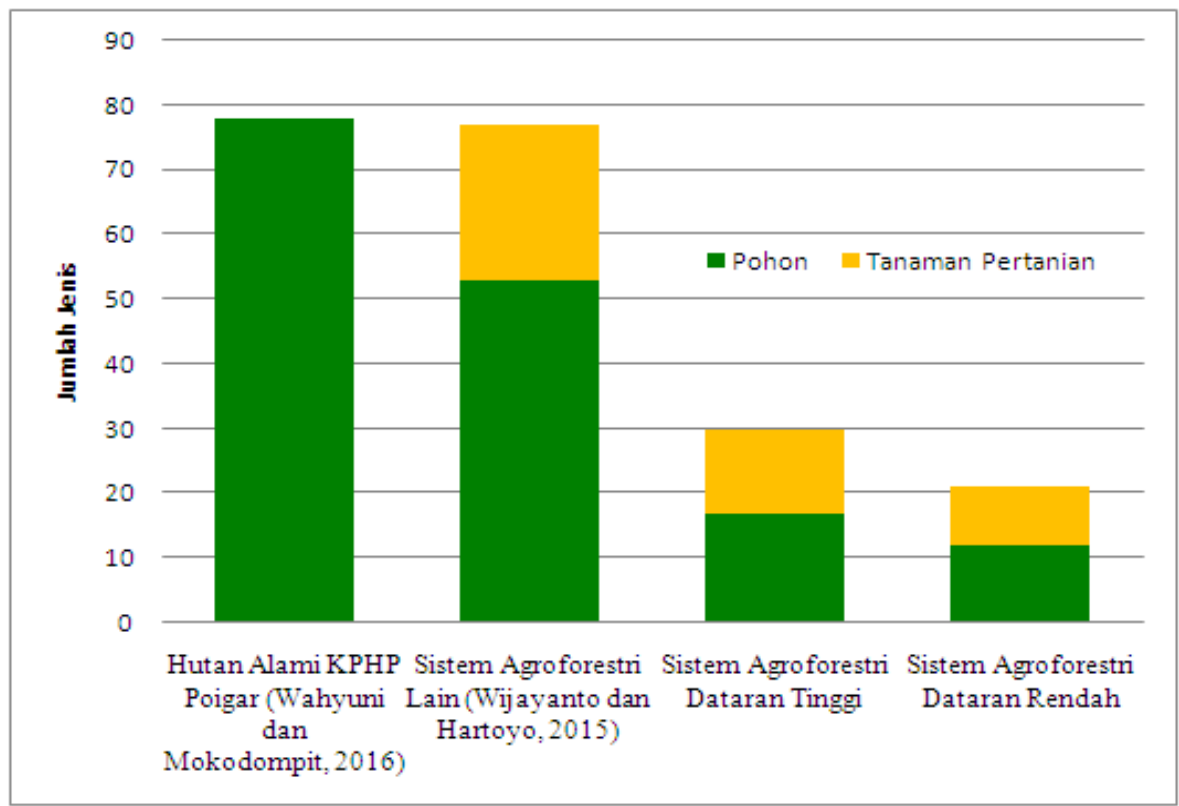

Gambar 3. Jumlah Jenis Tanaman di 4 Lokasi

(Figure 3. Numbers of Plant Species in 4 Location)

Tabel 3. Biomassa di Sistem Agroforestri Dataran Tinggi dan Dataran Rendah

(Table 3. Biomass at Lowland and Lowland Agroforestry System)

\begin{tabular}{lllc}
\hline & \multicolumn{2}{c}{ Sistem Agroforestri Dataran Tinggi } & \multicolumn{2}{c}{ Sistem Agroforestri Dataran Rendah } \\
\hline Nomor Lahan & \multicolumn{1}{c}{ Biomassa (Mg ha-1) } & Nomor Lahan & Biomassa (Mg ha-1) \\
\hline 1. & 6,49 & 1. & 0,25 \\
2. & 19,75 & 2. & 0,52 \\
3. & 3,30 & 3. & 1,55 \\
4. & 21,46 & 4. & 4,91 \\
5. & 7,66 & 5. & 4,00 \\
6. & 98,65 & 6. & 0,66 \\
7. & 0,34 & 7. & 2,72 \\
8. & 14,07 & 8. & 13,11 \\
9. & 92,25 & 9. & 8,54 \\
10. & 38,95 & 10. & 4,48 \\
11. & 28,58 & 11. & 1,38 \\
12. & 28,89 & 12. & 1,87 \\
13. & 33,69 & 13. & 2,26 \\
14. & 7,21 & 14. & 1,42 \\
15. & 9,69 & 15. & 4,44 \\
\hline Total & 410,97 & Total & 52,11 \\
\hline Rata-rata & 27,40 & Rata-rata & 3,47 \\
\hline
\end{tabular}




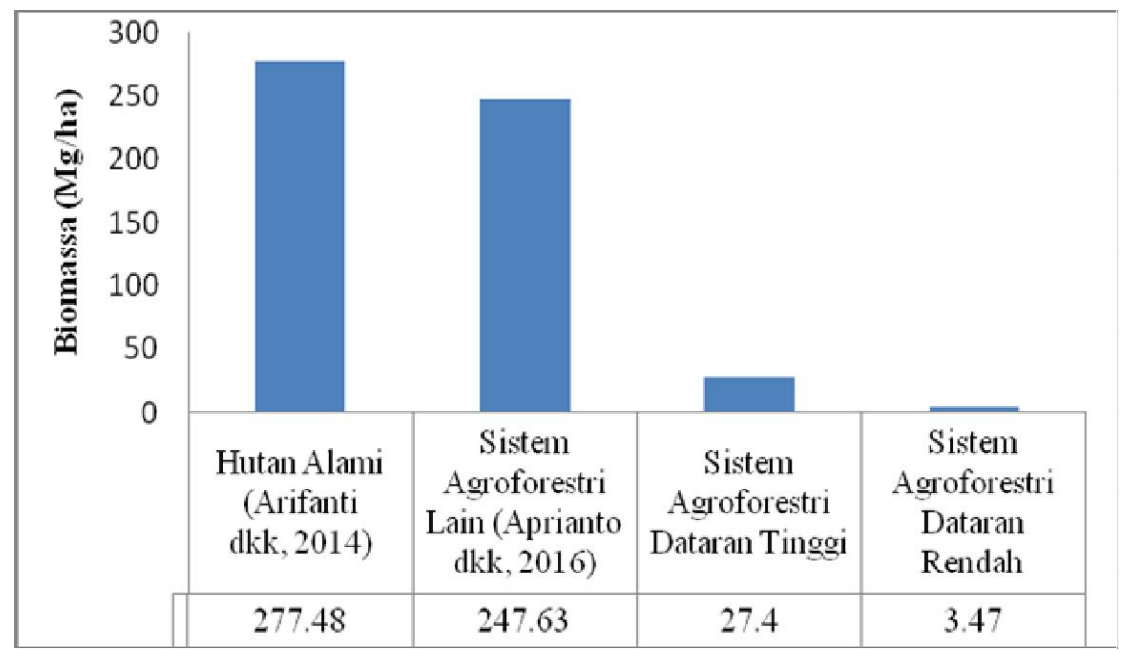

Gambar 4. Biomassa di 4 Lokasi

(Figure 4. Biomass at 4 Location)

Biomassa atas permukaan yang terdapat di sistem agroforestri dataran tinggi terutama dataran rendah Kabupaten Minahasa Selatan jauh lebih rendah dibandingkan dengan sistem agroforestri di Lampung. Masih rendahnya alokasi lahan untuk tanaman kayu mengakibatkan kondisi tersebut. Sebagian besar areal lahan ditanami tanaman semusim oleh petani. Sistem agroforestri yang baik harus memiliki fungsi ekologi dalam hal ini biomassa atas permukaan mendekati biomassa atas permukaan hutan alami. Tingginya biomassa suatu lahan menggambarkan tingginya karbon yang terikat dalam tanaman-tanaman kayu tersebut. Penanaman tanaman kayu ataupun tanaman pohon-pohon penghasil buah-buahan di sistem agroforestri dataran rendah dan dataran tinggi dapat memperbaiki fungsi ekologi pengikat karbon.

\section{KESIMPULAN DAN SARAN}

\section{Kesimpulan}

Di Kabupaten Minahasa Selatan, jumlah jenis tanaman dan jumlah biomassa yang terdapat di lahan-lahan sistem agroforestri dataran rendah lebih sedikit dibanding dengan yang terdapat di dataran tinggi.

\section{Saran}

Perlu dilakukan penanaman jenis tanaman lain, dalam hal ini tanaman pertanian dan terutama tanaman pohon agar dapat meningkatkan jumlah jenis dan biomassa sistem di dataran tinggi dan terutama dataran rendah di Kabupaten Minahasa Selatan agar mendekati fungsi ekologis hutan alami.

\section{DAFTAR PUSTAKA}

Achmad, B. dan R. H. Purwanto. 2014. Peluang Adopsi System Agroforestry Dan Kontribusi Ekonomi Pada Berbagai Pola Tanam Hutan Rakyat Di Kabupaten Ciamis. Jurnal Bumi Lestari 14 (1): $15-26$.

Anonim. 2008. Petunjuk Praktis Sifat-sifat Dasar Jenis Kayu Indonesia. Indonesian Sawmill and Woodworking Association (ISWA). Indonesia.

Aprianto, D., C. Wulandari dan N. W. Masruri. 2016. Karbon Tersimpan Pada Kawasan Sistem Agroforestry Di Register 39 Datar Setuju Kphl Batutegi Kabupaten Tanggamus. Jurnal Sylva Lestari 4 (1): 21-30.

Arifanti, V.B., I.W.S. Dharmawan dan D. Wicaksono. 2014. Potensi Cadangan Karbon Tegakan Hutan Sub Montana Di Taman Nasional Gunung Halimun Salak. Jurnal Penelitian Sosial dan Ekonomi Kehutanan 11 (1): 13-31. 
Ketterings, Q.M., R. Coe, M. van Noordwijk, Y. Ambagau, and C. A. Palm. 2001. Reducing uncertainty in the use of allometric biomass equations for predicting above-ground tree biomass in mixed secondary forests. Forest Ecology and Management 146 : 199 - 209.

Langenberger, G., V. Prigge, K. Martin, B. Belonias, and J. Sauerborn. 2009. Ethnobotanical knowledge of Philippine lowland farmers and its application in agroforestry. Agroforestry Systems 76 (1): 173-194.

Mansur, M.. 2003. Analisis Vegetasi Hutan di Desa Salua Dan Kaduwaa Taman Nasional Lore Lindu, Sulawesi Tengah. Jurnal Teknik Lingkungan, P3TL-BPPT 4(1): 1-7.

Mawazin, dan A. Subiakto. 2013. Keanekaragaman Dan Komposisi Jenis Permudaan Alam Hutan Rawa Gambut Bekas Tebangan Di Riau (Species Diversity and Composition of Logged Over Peat Swamp Forest in Riau). Indonesian Forest Rehabilition Journal 1 (1): 59-73.

Miles, P.D., dan W.B. Smith. 2009. Specific Gravity and Other Properties of Wood and Bark for 156 Tree Species Found in North America. United States Department of Agriculture.

Nair, P. K. R. 1993. An Intorduction to Agroforestry. Kluwer Academic Publishers and International Centre for Research in Agroforestry.Dordrecht / Boston / London.
Purwanti, R. 2007. Pendapatan Petani Dataran Tinggi Sub Das Malino. Jurnal Penelitian Sosial dan Ekonomi Kehutanan 4 (3): 257 269.

Sorenson, T. 1948. A Method of Establishing Groups of Equal Amplitudes in Plant Sociology Based on Similarity of Species Content and Its Application to Analyses of the Vegetation on Danish Commons. Kongelige Danske Videnskabernes Selskab, Biologiske Skrifter 5: 1-34.

Wahyuni, N.I., dan H.S. Mokodompit. 2016. Struktur, Komposisi Dan Keragaman Jenis Pohon Di Hutan Produksi Inobonto Poigar I, Kphp Poigar, Sulawesi Utara. Jurnal Wasian 3(1): 45-50.

Wijayanto, N. dan A.P.D. Hartoyo. 2015. Biodiversitas Berbasiskan Agroforestry. Prosiding Seminar Nasional Masyarakat Biodiversitas Indonesia 1(2): 242-246.

Zanne, A.E., G. Lopez-Gonzalez, D.A. Coomes ,J. llic, s. Jansen, S.L. Lewis, R. B. Miller, N. G. Swenson, M. C. Wiemann, and J. Chave. 2009. Data from: Towards a worldwide wood economics spectrum. Dryad Digital Repository. https://doi.org/10.5061/dryad.234 